\title{
DOMINIO DEL SENTIMENTALISMO SOBRE EL CINISMO EN LAS CINCO ADVERTENCIAS DE SATANÁS
}

\author{
Dorde Cuvardic García
}

\begin{abstract}
RESUMEN
Enrique Jardiel Poncela es uno de los más importantes escritores humoristas españoles de la primera mitad del siglo XX y Las cinco advertencias de Satanás uno de sus primeros intentos teatrales de aplicación del humor mecanizado. Representa una obra de transición en la que conviven el discurso sentimental (recurrente en sus primeras obras teatrales) con los incipientes atisbos del humor deshumanizado de obras posteriores. En esta comedia, el sentimentalismo se considera la conducta ideal de los personajes. El cinismo del dandi u hombre de mundo queda vencido por la sentimentalidad introducida por el personaje femenino romántico. El humor mecanizado irónico cede al discurso de la afectividad, circunstancia que se invertirá en sus posteriores obras.
\end{abstract}

\section{ABSTRACT}

Enrique Jardiel Poncela is among the most important Spanish authors of humor from the first half of the present century. Las cinco advertencias de Satanás, one of the first plays in which he uses mecanized humor, is a transitional work that joins sentimental discourse (common in his first plays) with glimpses of the dehumanized humor found in later works. In this comedy, sentimentalism is considered an ideal behavior for the characters. The dandy's cinism is overpowered by the sentimentalism of the female character and the ironic mechanized humor gives way to affective discourse. In future works, however, this situtation is inverted.

\section{Enrique Jardiel Poncela, autor que no envejece}

El teatro de Enrique Jardiel Poncela sigue representándose con asiduidad en España: su teatro no envejece. Según datos estadísticos de la Sociedad General de Autores de España (Pérez Coterillo 1995: 18), como autor dramático, ocupó entre 1982 y 1994 el cuarto lugar por número de representaciones (1477) y el tercero por número de espectadores (466 847), gracias al reestreno de siete de sus obras. Además, después de un período de desprestigio, su dramaturgia y obras son objeto de estudios y de recuperaciones. Las cinco advertencias de Satanás (1935), donde entran en conflicto el humor mecanizado y el discurso del sentimiento, sale del semiolvido y, por la moderación de la puesta en escena de sus recursos expresivos, desplaza a otras obras posteriores en el favor de la crítica. 
Durante la primera mitad del siglo XX, Enrique Jardiel Poncela renovó el género humorístico español junto con un número importante de escritores, cuyo representante más importante fue Ramón Gómez de la Serna. Recogiendo lo mejor de las técnicas humorísticas (juegos de palabras) y de los temas (típicos de la "alta comedia") de la dramaturgia comercial, conseguirá innovar la escena teatral de su tiempo, estancada por géneros como el "vodevil", la "revista", la "comedia musical", el "sainete" y las "comedias castizas". No busca una ruptura estructural y temática con el teatro comercial de su época, sino una evolución moderada pero persistente, rescatando para tal fin el ambiente de la comedia urbana comercial: reutiliza la representación de situaciones burguesas de los dramas populares. Enrique Jardiel Poncela, a comienzos de los años 30, se lanzó a la creación de comedias que ejecutaran sus concepciones personales sobre el humor "deshumanizado". Ocho comedias de este tipo fueron publicadas antes de la guerra civil (1936-1939), todas con marcados rasgos sentimentales, entre ellas, Las cinco advertencias de Satanás (1935).

La trama de esta obra es típica del teatro de Jardiel Poncela: amores desesperados, misterio demoníaco, realidad fantástica rompen la monotonía existencial de personajes ociosos y adinerados con posibilidades de tiempo y dinero para llevar vidas extravagantes y búsquedas idealistas o amorosas. Esta comedia se convierte en representante moderado de su "teatro inverosímil", que aspira a eliminar lo verosímil cotidiano y a implantar lo inverosímil realista de matiz extravagante. Este carácter está atemperado por los sentimientos de los personajes, tan importantes, dramáticamente, como sus juegos de palabras y chistes.

Victoria Urbano divide el humor teatral de Jardiel Poncela en dos grupos, según el tipo de técnica cómica que aplique. En primer lugar, las comedias cuyo rasgo dominante es la parodia, salpicadas de malicia e ironía (obras apoyadas en la comicidad del diálogo). El segundo grupo estaría conformado por la comicidad que se obtiene por medio de la deformación del lenguaje deshumanizado: por la ingeniosidad del pensamiento y el comportamiento excéntrico, desbordando a los personajes, se convierten en los protagonistas absolutos (1972: 179-80). Las cinco advertencias de Satanás pertenece al primer grupo. Esta obra es una de las mejores de Jardiel Poncela por la moderación de sus técnicas narrativas y humorísticas. El autor evita excesos de muchas de sus obras -señalados por Francisco Ruíz Ramón (1975: 274-5) y otros críticos-: no abusa de las situaciones explicativas y justificativas, en detrimento de la acción; consigue que no sucumba bajo una acumulación confusa de episodios y de personajes; no construye un final apresurado ni abusa del lenguaje ingenioso.

Las cinco advertencias de Satanás se sitúa en el ambiente típico del género de la alta comedia con la intención de estructurar una inversión paródica que desenmascare las acciones de los personajes burgueses como triviales, anodinas e incluso absurdas. Esta ambientación facilita el desarrollo de la excentricidad y del diálogo lógico/absurdo e ingenioso de los personajes: se aisla su marco situacional por motivos de estructura narrativa. Sin embargo, el uso de ambientes elegantes y seguros es una forma velada de denunciar la inestabilidad de la España de los años 30. Los personajes, hastiados de la vida mundana, se encierran en sus torres de marfil. Coral dice: "Me he construido un universo para mí sola. Y aquí hago lo que me gusta." (Jardiel Poncela 1990: 238) ${ }^{1}$. Más adelante, por medio del desarrollo de la afectividad entre Coral y Félix, Jardiel Poncela increpa a la burguesía para que salga de sus torres de marfil y conozca la sociedad circundante. 
Mientras que la realidad sociopolítica sólo se ofrece metafóricamente (aislamiento de los personajes respecto de la historia), no ocurre lo mismo con la evolución de las costumbres sociales. La sátira sobre las modas se convierte en tema para la hilaridad. Una parodia sobre nuevas costumbres sociales se ejecuta en el nudismo practicado por el personaje de Silvia. Jardiel Poncela tenía la facultad de eliminar la marca de tabú hacia costumbres novedosas.

\section{Triunfo del sentimentalismo sobre el cinismo}

Las cinco advertencias de Satanás es una comedia en cuatro actos estrenada en el Teatro de la Comedia, de Madrid, el día 20 de diciembre de 1935, siete meses antes del alzamiento militar que daría comienzo a la Guerra Civil Española. Es una comedia que trata de una búsqueda amorosa y de su temporal imposibilidad. Este es el argumento:

Félix es un dandi que ha buscado por muchos años el amor de su vida. Sin embargo, sus desengaños amorosos son comunes. Rápidamente se cansa de sus acompañantes y las abandona. Para indemnizarlas, les entrega una apreciable cantidad de dinero. Inmediatamente, estas mujeres consiguen una nueva pareja en la persona del "vividor" Ramón, otro dandi. Después de “despachar" a la última de sus amantes, Félix, en presencia de Ramón, recibe la visita de Satanás, de nombre Leonardo, cuyas características corresponden también a las de cualquier dandi u hombre de mundo de actitud cínica. Félix es objeto de las simpatías de Leonardo (conoce su hastío y el estado lamentable de su vida amorosa); por tal motivo, le lanza cinco advertencias sobre su próximo futuro: la primera, conocerá pronto a una mujer; la segunda, se enamorará rápidamente de esa mujer; la tercera, se arrepentirá de haberla enamorado y de haberse enamorado él mismo; la cuarta, arrependido de quererla y ella de haberle querido a él, la dejará en brazos de otro hombre a los tres meses; la quinta y última advertencia será señalada al cabo de un año. Poco después Félix conoce a Coral, vecina que llega a la casa de Félix en estado de solambulismo. Esta es la mujer elegida por Leonardo. Tres meses después, para evitar la cuarta advertencia (arrojar a la amada en los brazos de otro hombre), Félix se aleja de Coral y se hospeda secretamente en Niza. Sin embargo, el destino es implacable; por fin se aclara el sentido de la penúltima advertencia: Coral es hija de Félix. Este personaje, arrepentido de haberse enamorado de su propia hija, se la entrega a su amigo Ramón: se cumplen las predicciones. La quinta advertencia, manifestada un año después, consiste en la pérdida de la juventud de Félix: su primer nieto le convierte en abuelo.

Antes de explicar las actitudes de los personajes es necesario explicar algunas particularidades estructurales de esta obra de Enrique Jardiel Poncela.

Las acotaciones del guión teatral no remiten únicamente a los decorados y los gestos o movimientos de los personajes; en muchas ocasiones se ofrece una completa descripción psicológica de los mismos. Las acotaciones -sólo apreciadas por los lectores- constituyen un refuerzo de las actitudes, gestos, vestimenta y modos de hablar de los personajes en el escenario. He aquí un ejemplo:

(...) le paralizan las palabras de Coral, la cual comprende de pronto que FÉLIX no es un seductor corriente, y que no actúa en ese sentido. Sospecha lo que 
realmente pasa por el interior de FÉLIX: su deseo de irse, el que la juzga como un peligro, y le lanza su acusación, aunque con cierta timidez todavía. (229)

Estas acotaciones son propias de los géneros narrativos no dramáticos. En ocasiones, Las cinco advertencias de Satanás se siente como una novela psicológica dialogada. Sin embargo, el desarrollo de la trama se somete a la acción.

Los escenarios son apropiados para el desarrollo de la comedia sentimental. La elección de un hotel (vestíbulo y un par de habitaciones: ambiente cosmopolita de un balneario) como escenario de los equívocos del tercer acto representa un acierto narrativo, pues constituye un espacio ideal para las situaciones de enredo que se viven en ciertos momentos del drama.

Por otra parte, las viviendas particulares se impregnan de los gustos de las personas que los habitan. La decoración objetual se humaniza: expresa los gustos y sentimientos de sus dueños.

\subsection{La ironía del cinismo y la sentimentalidad del romanticismo: su fusión dramática a través de lo cómico sobrenatural}

Centrándonos en el humor, su manifiestación principal es la ironía retórica, en dos de sus vertientes: los dobles sentidos y los juegos de palabras. El principio más utilizado es el de contrariedad o equívoco (contrariedad de Isaak ante el desperdicio de dinero de Félix, contrariedad de éste ante la imposibilidad de alcanzar la felicidad, contrariedad de Alicia ante el desplante de Félix). En cuanto a la organización del discurso de los personajes, la ironía se utiliza para evidenciar la distancia entre lo que se es (un dandi excéptico) y lo que se debería ser (un buen padre de familia que ama a su esposa e hijos).

En cuanto al sentimentalismo, su manifestación situacional más común es la expresión del alma romántica (Coral) y del alma sexualmente atormentada (Félix), y la aceptación personal de las situaciones paradójicas que el Destino -en la figura del demonio "Leonardo"- impone (Félix nuevamente). Sorprende, en Las cinco advertencias de Satanás, que el Romanticismo literario puesto en burla por Jardiel Poncela en tantas de sus obras (como cosmovisión por evitar) sea usado como retórica por aplicar: se justifica la manifestación expresiva de la sentimentalidad de las figuras masculinas -tradicionalmente atrofiada- hasta vencer el cinismo cotidiano, expresado por la ironía excéptica, burlesca y resentida. En esta obra, a diferencia de otras de Jardiel Poncela, se defiende la asunción del sentimentalismo. Los personajes soportan las situaciones típicas de este subgénero (vacío existencial que debe ser llenado por el amante, el amor como don inevitable del destino, el tormento amoroso) antes de alcanzar el idilio amoroso. La defensa del romanticismo refleja la búsqueda sentimental que vivió el autor ante sus recurrentes fracasos amorosos.

Por otra parte, el erotismo desbordante de sus novelas sólo se manifiesta a cuenta gotas. El amor está enfocado dentro de la perspectiva romántica, muy lejos de la perspectiva erótica empleada por Jardiel Poncela en otras obras dramáticas y, sobre todo, novelas, tales como Pero... ¿hubo alguna vez once mil vírgenes?, ¡Espérame en Siberia, vida mía!, y Amor se escribe sin hache. El único elemento erótico de Las cinco advertencias de Satanás es el personaje de Silvia, practicante nudista, demasiado cándida para ejercer una práctica que exige sigilo y precaución. Precisamente el ejercicio exhibicionista de su inocencia en un 
contexto no nudista constituye la base paradójica que permite la posiblidad de realización de algunas situaciones jocosas.

Lo cómico sobrenatural emerge en la situación humana cotidiana para transformarla en situación trágica. Una vez solucionada esta última, se alcanza la felicidad que proporciona la sentimentalidad. Sólo los actores incitados por el mundo sobrenatural son capaces de sentirlo como real. Lo sobrenatural necesita manifestarse de forma natural para incorporarse a la realidad. De ahí la posibilidad de introducir la realidad sobrenatural en la escena, pues se manifiesta materialmente en el mobiliario. Satanás, invisible, mueve un sillón (efecto técnico).

Aunque las advertencias de Satanás (Leonardo) constituyen la situación de base inverosímil que desencadena la verdadera acción de la obra, el resto del argumento se mantiene dentro de un desarrollo argumental verosímil (pero dependiente de muchas relaciones causales), pues no representa sino el desarrollo de una situación sentimental bastante común.

Lo cómico sobrenatural sirve como actividad que ayuda al triunfo del sentimentalismo. Leonardo, el demonio "bueno", busca que cada personaje se ubique correctamente en el puesto que debe ocupar en la red de las relaciones amorosas.

\subsection{Los personajes como manifestación de comportamientos arquetípicos cínicos, cómicos y sentimentales}

Los personajes representan papeles que toman como base la vida ociosa de la burguesía madrileña. Sin embargo, y este factor juega a favor de la calidad de la obra, no son simples mecanismos de creación de lenguaje ingenioso, como ocurre con bastantes comedias posteriores de Jardiel Poncela, sino que poseen grandes dosis de humanidad: ternura, crueldad, indiferencia. En suma, no se encuentran dualismos morales extremadamente marcados.

Esta obra posee pocos personajes; en realidad, como toda comedia sentimental, no necesita muchos. Nueve personajes que cumplen papeles estereotipados; sin embargo, se usa con exceso este recurso, utilizado aquí como elemento de comicidad, para que quede desenmascarado y así el público se de cuenta del convencionalismo social que supone la adjudicación de actitudes y comportamientos fijos a funciones humanas cotidianas, en este caso, las funciones del administrador Isaac o del dandi o vividor Ramón. Además, en ciertos personajes se pierde la estereotipia: surge la evolución de la actitud (Félix, Ramón).

Cada arquetipo masculino encuentra su equivalente femenino: cuatro personajes por cada sexo. Satanás es una figura solitaria que no tiene reflejo especular en ningún otro personaje.

He aquí las equivalencias:

Figuras masculinas

Félix

Ramón

Isaak

Pedro
Figuras femeninas

Coral

Alicia

Silvia

Pepita 
Tres personajes manifiestan evolución psicológica: Félix, Coral y Ramón. Los demás no constituyen sino comparsas que facilitan las intenciones de los protagonistas (Pedro, Pepita, Isaac, Silvia, Alicia).

Respecto de los recursos cómicos, la ironía, los chistes, los juegos de palabras y los equívocos ingeniosos son manifestados por Ramón; el horror cómico, por Leonardo; lo ridículo, por el criado Pedro y el judio Isaak; y lo excéntrico, por la nudista Silvia.

Como elemento único e irreemplazable está Satanás. No se trata de un demonio sombrío, terrorífico y castigador, sino alegre, pícaro; en fin, un demonio bueno que quiere contribuir a la felicidad de Félix sin ningún interés pecaminoso (sin que posea la función de un pobre diablo). Este demonio representa la espiritualidad de un dandi en proceso de transformación. Se comporta como sus colegas terrenales (Félix y Ramón), pero es más lúcido respecto del futuro cercano. Con la intención de enredar la vida humana, les comunica su más inmediata vida: abandonarán la vida de mundo cosmopolita para asumir la vida hogareña: Ramón como marido, Coral como esposa y Félix como padre. Se trata de un diablo travieso pero bueno: descubre parte del Destino (aunque de forma incompleta) contraviniendo las reglas del pacto del más allá (el ser humano no debe conocer el futuro). De todas formas, Leonardo quiere allanar el camino de la felicidad a Félix e instarle a no resistirse ante su futuro; sin embargo, ¿cómo aceptar unas advertencias tan ambiguas? De ahí los trabajos inútiles de Félix: alcanzará el amor sentimental, pero mediante un camino distinto al esperado.

Ramón es el personaje que transmite la comicidad. Es el interpretante de los clásicos recursos humorísticos de Jardiel Poncela: la extravangancia de las costumbres y el cinismo existencial del personaje expresados en una ironía sembrada de juegos de palabras, equívocos y frases ingesiosas. El personaje de Ramón ejecuta, por un lado, la ironía puesta al servicio del cinismo de las clases ociosas y, por otro, los juegos de palabras ("pasatiempos linguísticos").

Para ello necesita de personajes que le sirvan como plataforma para el dialogismo formal (Ramón activo; sus comparsas, pasivos), necesario para desempeñar su humorismo: este es el caso de Pedro, criado que no tiene voz opinativa, pues representa el eco de la voz del señor. Por debajo de este dialogismo apariencial, se da un monólogo del discurso misógeno producto del fracaso amoroso del dandi. El personaje cínico necesita de otros personajes comparsa para desarrollar al máximo las posibilidades, en su discurso, de ironía retórica, entre cuyas estrategias se encuentra la ironización de las propias costumbres:

RAMÓN.-Tráeme jamón cocido, huevos duros, frutas frescas, mermeladas, tostadas con mantequilla y café con leche. (A Félix, en son de excusa.) Perdona, pero ya sabes que yo tengo costumbre de desayunar a la inglesa. (197)

Pero también ironiza otros muchos asuntos; por ejemplo, el lugar común del lenguaje:

ALICIA.- (Con la mano tendida.) Orellana ¡Qué sorpresa! No nos veíamos hacía un siglo.

RAMÓN.- (Ayudándose a quitarse la capa.) Muchas gracias, porque hacía cuatro meses nada más. (195) 
Gran parte del primer acto constituye una declaración de principios del cinismo. Es común en Jardiel Poncela iniciar sus obras con la exposición de comportamientos sociales antes de narrar las acciones de los personajes.

El cinismo de Ramón (mayor) y de Félix (menor), manifestado por la ironía retórica, tiene como principal objeto de burla a la mujer y como principal conducta existencial el excepticismo amoroso (el cínico no posee o no debe manifestar sentimientos afectivos, sobre todo los amorosos). De ahí el misoginismo manifiesto. La mujer es un ser despreciable y débil y el hombre debe decidir sobre la libertad de ésta: sus funciones y cualidades se ironizan con el objeto de burlarse del ser femenino como tal.

\subsection{El cinismo: actitud de la personalidad insegura ante las situaciones que no controla}

El dandi u hombre de mundo, figura misógena, seductora y cínica por excelencia, está representado por Ramón y Félix.

En la presente obra encontramos dandis que vivieron tiempos mejores y que ahora se refugian en la excentricidad y en un círculo reducido de amigos. Ya no viven en los años veinte y están inmersos en la desesperanza que vive España en los años treinta. Su actitud no está conformada por la pérdida de valores morales, sino por su ausencia.

Félix y Ramón practicaron en sus mejores tiempos la ironía jactanciosa, pero empiezan a ejecutar la ironía amarga ("la vida es una broma de mal gusto" 214). El más acabado ejecutante de este tipo de ironía es Félix.

El dandi no tiene objetivos en la vida; ni siquiera posee objetivos amorosos; su práctica amorosa es asumida como juego (que tarde o temprano termina rompiéndose por su culpa). El "dandi" en fase crepuscular es un hombre amargo y no deja de expresarlo por medio de la ironía hiriente. Según señala Antonio Muñoz Molina , "la estética de los antiguos dandis escondía una moral de la desesperación" (Muñoz 1993: 134). Así es; el hombre de mundo no sabe relacionarse con las personas de su círculo íntimo, sobre todo con las mujeres. El cinismo constituye la actitud amarga, defensiva y autojustificadora que ayuda a su portador a olvidar sus inestables y borrascosas relaciones personales (situaciones límite).

El dandi en crisis extrema esta actitud al cambiar externamente de comportamiento: se presenta pasivo en su conducta y activo en su expresividad verbal, que adquiere rasgos vituperinos ante el objeto de deseo que no llega a alcanzar: la mujer. Además, se presenta el discurso de la autolástima. El humor irónico corrosivo es un rasgo verbal más visible de su personalidad.

Rita María Porras León, interprentando el significado del humor en Sigmund Freud, señala que:

(...) la actitud humorística es de superioridad frente al sufrimiento propio o ajeno. Se fortalece el superyo (mayor investidura) y así se logra minimizar al yo sufriente, rechazando la realidad y sirviendo a una ilusión. (Porras 1995: 83)

Ramón se encuentra resentido al no haber conseguido jamás un un amor verdadero. Ha sufrido varios desengaños amorosos: se cansa pronto de las mujeres (a causa de su carácter exigente). No piensa que él mismo es quién debe cambiar de actitud, no sus amantes: prefiere 
atacar la personalidad de su pareja y, por ende, la de las mujeres en general. De ahí proviene su misoginia: "el superyo quiere consolar al yo y ponerlo a salvo del sufrimiento" (Porras León 1995: 83). Sin embargo, el humor salvador es de raigambre negativa: enmascara los problemas sentimentales. Es un humor dirigido hacia sí mismo: Ramón es el destinador y el destinatario de su humor. Este humor le permite rechazar a su propia persona como origen de los fracasos amorosos: el juego linguístico y la ironía amarga fortalecen temporalmente el «superyo», que necesita mantenerse a un nivel elevado de estima. En el caso del humor negativo, el «superyo» no discierne la inutilidad de la actitud vital mantenida: la misoginia y el cinismo ante las personas.

La mujer es la representante de todos los vicios y defectos; sus cualidades adquieren una connotación despreciativa o denigrante: "En la mujer, un ronquido se perdona peor que un pasado" (192); "De gastar no hay que hablar: gastará un disparate" (192).

El discurso del dandi se llena de prepotencia al referirse a las relaciones hombre-mujer:

Todas las mujeres se creen imprescindibles. (201)

No hay nadie que peor conozca su oficio que la mujer. (201)

El hombre que no fue educado para respetar a la mujer se convierte en misógeno; exige demasiado de ésta y la trata como un objeto; al revelarse la indiferencia o el enfrentamiento de la mujer ante la actitud del hombre surge el desengaño amoroso de éste. A pesar de todo, el cínico siempre espera un amor definitivo:

PEDRO. - Y un hombre cínico en el amor, ¿cree el señorito que puede llegar a dejar de serlo?

RAMÓN. - Sí, si tropieza en su camino con una gran pasión. (190)

El dandi no podrá encontrar ninguna gran pasión mientras no deje de ser cínico. En las mismas palabras de Ramón se señala que "hasta que llegue el momento romántico, nosotros nos abrazamos al cinismo" (93). He ahí el problema: el hombre de mundo debe abandonar su cinismo en toda relación con su amante, no sólo en los momentos románticos. A pesar de ciertos atisbos de cambio al final de la obra, Ramón mantiene su cinismo en los momentos más serios. El amor puro que confiesa Félix respecto de Coral es ridiculizado por Ramón, cuando todavía es excéptico en asuntos de amor. En dos ocasiones se mantiene un duelo dialogal entre el dandi renegado (Félix) y el dandi en activo (Ramón); señalemos una de ellas:

FÉLIX. - ...y sin embargo, si pudieras oírme en serio unos instantes...

RAMÓN. - He perdido la costumbre; pero haré un esfuerzo.

La segunda ocasión se presenta al final del cuarto acto:

FÉLIX. - Quizá los dos sentimientos se mezclan ya en mí, y el uno me empuja a decirte que te lleves a Coral, y el otro me arrastra a dudar si eres digno de ella. 
RAMÓN. - (Sonriendo.) Absolutamente paternal, Félix. (257)

El compromiso en el amor se contesta con el excepticismo de la ironía.

El cinismo se expresa mediante frases declamatorias, típicas de decálogos y de libros de citas. Gracias a las frases de Ramón podemos crear el retrato robot psicológico del dandi (la personalidad cínica gusta de describirse a sí misma psicológicamente):

- Tarda uno más tiempo en cansarse de ellas (hablando de las corbatas) que de las mujeres. (189)

- Siempre he creído que uno y otro somos, en el fondo, dos románticos, cosa que, al fin y al cabo, les sucede a todos los cínicos. (189)

- Un buen cínico, Pedro, no debe olvidar las utilidades de la servidumbre. (190)

- Ser cínico es volver a escribir lo que ya habíamos tachado. (190)

- Hasta que llegue el momento romántico, nosotros nos abrazamos al cinismo.

(193) (El hombre de mundo sólo vive el momento presente).

- El romanticismo es una afección gástrica. (214)

- El cinismo de un hombre soltero es al antesala del matrimonio. (275)

Estilísticamente, esta discursividad ingeniosa se parece a la greguería ramoniana: recordemos que algunas frases ingeniosas que Enrique Jardiel Poncela pone en boca de sus personajes en Las cinco advertencias de Satanás también están publicadas en su libro "Máximas mínimas", especie de colección de "greguerías ramonianas" jardielescas.

El cinismo puede hacer referencia a la deshumanización de las cualidades humanas (proceso de cosificación), procedimiento mostrado en varias oportunidades en el primer acto:

La realidad está en que, en cuestiones de amor, la mujer y el hombre somos ferrocarriles de trayecto limitado, y como la existencia es un viaje muy largo, se ve uno obligado a cambiar varias veces de tren. (201)

El amor entre los seres humanos asume connotaciones propias de la monótona vida cosmopolita:

Al cabo, veinte años de viajes se resumen en la figura borrosa de un empleado de Aduanas, que pide el mismo pasaporte en siete idiomas diferentes, y veinte años de amores se resumen en la figura borrosa de una mujer, que pide siete sombreros diferentes en el mismo idioma. (204)

Sin embargo, Ramón, dandi en crisis, aunque en mucha menor medida que Félix, comienza a darse cuenta de su actitud desfasada. La ironía amarga no sólo le servirá para manifestar el despecio a los demás, sino también para expresar sus dudas ante la visión de mundo sostenida hasta ahora; Ramón, dirigiéndose a Félix, señala:

Tu has procedido siempre como un cínico, siendo en realidad un romántico, y yo, romántico perdido en el fondo, he vivido en pleno cinismo. Pero en ti y en mí, a lo largo de la vida, no ha habido más que una ambición: el amor. (255) 
Gusta de referir juegos de palabras o ingeniosidades con un lenguaje objetual que remite a las personas (deshumanización de las cualidades humanas). Ejercita el humor negro para descargar su hastío anímico. He aquí otros dos ejemplos de deshumanización del lenguaje de la emotividad:

El amor es como una goma elástica que dos seres mantienen tirante, sujetándola con los dientes: un día, uno de los que tiraban se cansa, suelta, y la goma le da a otro en sus narices. (212)

Uno también tiene sus ilusiones sentimentales... Y una mujer que renuncia a cobrar veinte mil duros... ¡Si esa no es la mujer ideal! (213)

El desahogo se consigue con el lenguaje deshumanizado. Los dandis descubren que el cinismo era la actitud defensiva ante los resultados inútiles de las experiencias amorosas. Aprenden a conocer el amor sentimental (Félix, sobre todo).

\subsection{El sentimentalismo: actitud que debe ser asumida como expresión de la capacidad para amar}

Félix es el hombre de mundo que se encuentra en crisis existencial. La partícula de añadida al apellido permite indicar que pertenece a una familia de alcurnia. Deja el cinismo para abrazar el sentimentalismo. Con esta nueva visión de la realidad podrá conseguir un amor duradero, aunque el camino para alcanzarlo esté surcado de paradojas: provoca inintencionadamente situaciones que trata de evitar.

Félix siente miedo del Destino, pero en realidad teme el paso del tiempo. Tiene miedo de abandonar su vida mundana y de envejecer.

Al conocer a Coral, las sospechas de Félix sobre el cambio próximo que va a experimentar su vida se acrecientan. Su despedida de Alicia ya expresaba una voluntad real de dejar atrás su vida anterior.

El eje del segundo acto está montado sobre la sospecha, por parte de Félix y de Coral, de que sus vidas van a cambiar próximamente. La paradoja del segundo acto se presenta porque Félix siente miedo de lo ya explicado y conocido por Satanás, y Coral de lo inexplicable y de lo desconocido. En ambos casos se trata del mismo asunto. La ironía amarga ocurre porque Félix lo sabe todo, y el espectador está en idéntico nivel de conocimiento, mientras que Coral lo ignora todo. En el segundo acto, donde se produce el encuentro entre Coral y Félix, se describe a la mujer como ser moralmente inferior: necesita la protección masculina. La asunción del romanticismo en Félix pasa por la protección afectiva de la mujer.

La transición afectiva que sufre desde hace tiempo, su hastío en las relaciones amorosas, se ve precipitada por la aparición de Coral, primera mujer de la que se enamora verdaderamente. En Coral no verá a la mujer "objeto", sino a la mujer "persona". Pero la primera experiencia verdaderamente sentimental (en el mejor sentido de la palabra) de Félix no es un camino fácil. El verdadero amor afectivo es difícil de lograr y el argumento de la obra expone esta difícil situación. Aunque Félix esperaba otro tipo de amor, triunfa la actitud sentimental del amor 
paterno-filial sobre la actitud cínica del amor carnal. Se completa el cambio de su visión de mundo cuando conoce su nueva condición: reconoce que su época de seductor ya pasó y que debe asumir el papel de padre y, a corto plazo, el de abuelo. En suma, Félix no tiene más remedio que aceptar convertirse en una especie de patriarca familiar y, en consecuencia, los personajes redefinen sus funciones.

La personalidad de Félix se encuentra en transición. Se aleja progresivamente de la actitud vital de Ramón para acercarse a la de Coral, aunque sabe que camina por terreno paradójico.

Este amor es inestable (no sabe que actitud asumir ante Coral), pero propicia su cambio amoroso. La lucha paradójica contra el Destino permite aflorar en Félix una defensa arrolladora a favor del amor idealista. Se siente tan enamorado de Coral que prefiere mantenerse alejado de ella (sin poseerla) hasta que se cumplan las advertencias de Satanás. Su actitud férrea y constante al enfrentarse a paradojas inevitables (con el entusiasmo y la pertinencia de un joven enamorado) constituye la mejor prueba de su nueva conducta ante el amor.

Félix necesita aceptar nuevas situaciones para ser feliz; la aceptación de una situación (el éxito de una prueba) le llevará, más adelante, a enfrentarse y aceptar otra; mientras no acepte todas las pruebas impuestas por el amor sentimental, Félix vivirá atormentado. He aquí las pruebas:

1. Aceptar que está "enamorado" de Coral.

2. Aceptar los acontecimientos (las "advertencias") que depara el Destino a los enamorados.

3. Aceptar a Coral como hija.

4. Aceptar su próxima condición de abuelo.

Cada nueva aceptación le aleja de la actitud del dandi y le aproxima a la actitud del hombre hogareño y sentimental. Con la aceptación de la última prueba se completa su cambio de actitud. La frase final de Félix es toda una declaración de principios, pues responde al discurso de la claudicación: "Pedro, tráeme el batín de casa. Esta noche no salgo". (281) Cuando llevaba vida de dandi compraba la renuncia amorosa de mujeres enamoradas; ahora debe aceptar el amor filial. El abrazo de la vida sentimental se corresponde con el rechazo de la misoginia que conservaba su actitud pasada.

He aquí las etapas por las que atraviesa la actitud de Félix:

1. Actitud cínica-prepotente del dandi en plenitud de su actividad amorosa.

2. La inestabilidad de esta actividad le conduce a una etapa de crisis, manifestada en una actitud cínica-amarga (Félix está por terminar esta etapa; Ramón la inicia).

3. La aceptación del romanticismo como parte de la nueva actitud que asume ante la mujer (personaje que deja de ser un Objeto de Deseo para convertirse en sujeto amado). Es necesario destacar que la actitud sentimental ante el sujeto amado se puede manifestar tanto en el amor carnal como en el amor filial. Félix no abandona su nueva actitud amorosa sentimental al descubrir que su posible futura amante es, en realidad, su hija. Es más, el hecho de mantenerse tanto tiempo fiel a Coral hasta el momento de su reencuentro (esperando el momento de algún posible matrimonio, una vez superada la oposición del Destino), constituye una prueba de su aceptación del amor idealista.

Coral es un personaje cuya visión del mundo y estado de ánimo pertenecen a la sentimentalidad rosa: romántica, idealista. Es el personaje sentimental donado por el Destino que 
precipita la adopción del romanticismo por parte de Félix y Ramón. Primero arrasta a Félix (este personaje y Coral protagonizan los momentos sentimentales; los demás personajes, los momentos jocosos) y, posteriormente, a Ramón, en el amor sentimental (que puede ser complementario del carnal). En ella están representados los valores de la heroína del folletín: casta, ingenua, bella, imaginativa, entusiasta, idealista y romántica:

También me gusta ver las puestas de sol en el campo, y los escaparates en la ciudad. (Cambiando de tono otra vez, voluptuosamente) Y también me gusta tocar terciopelo..., y darme polvos con una borla de plumas... (239)

Coral es una chica que, como toda romántica que se precie, también se excita al transgredir un poco las convenciones:

Y cuando llueve o hay niebla, me gusta callejear envuelta en un impermeable y sintiendo la humedad en la cara y en el pelo... (239)

Pero también encuentra su mayor placer en la creación de mundos idílicos:

$\mathrm{Al}$ anochecer, muchos días me refugio aquí, me siento en uno de esțos sillones, cierro los ojos y vivo todo lo que quisiera vivir (239).

Las cinco advertencias de Satanás comienza en un momento coyuntural para los tres personajes principales: tanto Félix y Coral como Ramón se encuentran en un momento de hastío o vacío amoroso que debe ser llenado por la sentimentalidad. Necesitan un sujeto a quien amar. De ahí surge un triángulo en el que cada vértice busca encontrar un amor distinto.

- Coral: busca un amor romántico (que más adelante puede convertirse en carnal)

- Félix: busca, al mismo tiempo, un amor sentimental y carnal (después de disfrutar sólo de los amores carnales).

- Ramón: busca un amor carnal (sólo más adelante comprende que también busca en Coral el amor idealista).

El discurso retrospectivo de Coral, lleno de tópicos de folletín, narra sintéticamente la vida de la heroína. El decir (monólogo o diálogo) explica y a la vez desencadena y acelera la acción y el conflicto dramáticos (rasgo común del teatro de Jardiel Poncela).

A través de Coral se introducen algunos temas recurrentes de la novela folletinesca, de la novela sentimental o de la novela por entregas (Ferreras 1972: 254-5):

Primero, el tema de la orfandad. En el folletín sentimental, la huérfana pobre encuentra al final de un largo camino a sus padres, que siempre son ricos, poderosos, bondadosos y honrados. En el caso de Las cinco advertencias de Satanás se produce una variante: Coral es una huérfana rica, circunstancia que le evita los sufrimientos de la miseria (eludiendo, además, un enfoque más melodramático).

Segundo, el tema de la reconquista de lo perdido. Félix y Coral buscan un amor afectivo (posiblemente carnal) y encuentan, respectivamente, una hija y un padre. Juan Ignacio Ferreras señala que el tema del reencuentro o de la reconquista de lo perdido es, narrativamente, muy esquemático: 
(...) el tema de la reconquista está practicamente resuelto de antemano, todos los personajes pueden aparecer desde el primer momento, etc. Se trata solamente de contar no cómo, sino que la heroína o el héroe vuelven a encontrar a sus padres..." (1972: 255)

Sin embargo, Las cinco advertencias de Satanás va más allá del reencuentro, pues señala los problemas que puede acarrear este acontecimiento. En suma, en la novela sentimental el encuentro entre el padre y la hija constituye la solución de la trama; en Las cinco advertencias de Satanás, en cambio, representa el desencadenamiento de los problemas de los personajes. Esto sucede porque el reencuentro padre-hijo está precedido por el encuentro enamoradoenamorada.

En suma, Jardiel Poncela procedería como los mejores autores de las novelas folletinescas (según la opinión de Juan Ignacio Ferreras), es decir, combinando el tema del reencuentro con el tema de la conquista del amor idealizado. Primero, procedería a la idealización amorosa, que finalmente acabaría vencida por el reencuentro familiar. El tema de la idealización es anterior y el del reencuentro posterior.

\section{Funciones actanciales de otros personajes}

Los antecedentes de los criados jardielescos se encuentran en los criados del teatro greco-romano, que aconsejaban -función de cómplices- a sus amos (Menandro). No responden a la figura del criado del teatro medieval -por ejemplo, los consejeros hipócritas y soeces de $\mathrm{LaCe}$ lestina. Pedro, como todo criado jaridielesco, es fuente de comicidad por manifestar mediante una ironía tranquila y elegante la sorpresa y el desconcierto que le producen las actitudes excéntricas de su señor y de sus amistades. Es depositario de las inquietudes de su señor y de los amigos de éste y facilita sus acciones. Pepita, la criada de Coral, no pasa de ser un accesorio circunstancial.

Silvia, la chica nudista, es un persoanje-comparsa que ofrece una nota humorística y extravagante, aunque mayor importancia reviste Isaak, personaje comparsa que actúa como agente receptor de la comicidad manifestada por los otros personajes hacia su comportamiento. Jardiel Poncela extrema las cualidades que posee el judío en el imaginario colectivo para desenmascarar el uso estereotipado de esta figura en la producción cultural del mundo occidental. Extremando la tipicidad (tacañería, excentricidad, temperamento huraño) del personaje, permite al espectador comprobar la falsedad de los estereotipos adjudicados al judío, alcanzándose el máximo nivel de desenmascaramiento en el propio discurso de Isaak: "¿Tendrá usted el valor de decir que los judíos somos tacaños?" (198)

El choque de costumbres conduce a la paradoja del comportamiento excéntrico: el comportamiento inusual (práctica minoritaria) cae dentro de este tipo. Isaak comparte con Ramón el comportamiento excéntrico; además, los dos están sexualmente insatisfechos. La actitud excéntrica constituye una llamada de atención hacia sus problemas sexuales.

Alicia, otro personaje-comparsa, se convierte en sujeto de burla de los protagonistas. Como mujer repudiada que desconoce las intenciones del amante, constituye la figura que funge como instrumento que, al suscitar una situación equívoca, desata la comicidad. Representa a 
la mujer-objeto despreciada por el misógeno (Félix) que todavía no encuentra el objeto de enamoramiento. La mujer debe cumplir el papel de seductora; es despreciada cuando no satisface las expectativas del amor carnal del dandi. La mujer debe demostrar su utilidad; el hombre, no.

\section{Conclusiones}

Las cinco advertencias de Satanás constituye una defensa de la vida sentimental y hogareña y un rechazo de la vida cínica del dandi u hombre de mundo. Según las ideas propuestas en la obra, el continuo fracaso amoroso del dandi (cuya culpa proviene de su propio comportamiento, pues asume sus relaciones con las mujeres desde un enfoque exclusivamente carnal y lúdico) se soluciona con la aceptación de su afectividad sentimental y de la necesidad de expresarla emotivamente. La guerra de los sexos se supera gracias al desenlace de la comedia sentimental. El dandi debe olvidar los valores y prejuicios aprendidos en su proceso educativo y asumir su existencia como ser afectivo (receptor y donante).

Satanás, por medio de su instrumento, Coral, propicia y precipita la evolución del alma del dandi. Este tipo de hombre abandona su cinismo (aparta, primero, su ironía jactanciosa -se cree superior a las mujeres y las manipula-; después, aparta su ironía amarga -se da cuenta de sus fracasos y se dedica al ataque verbal) para abrazar seguidamente la actitud sentimental manifestada en la conducta romántica (Ramón señala en cierto momento que todo cínico es un romántico en el fondo).

Félix y Ramón son los sujetos cuya evolución moral debe ser precipitada (se elige el momento de hastío existencial para ejecutarse). Abandonan su relación con sus acostumbrados personajes comparsa (dialogantes de la práctica humorística irónica de los dandis) para entrar en la esfera de influencia afectiva de Coral, cuya puerta de acceso les introduce por un camino repleto de pruebas -la felicidad no se alcanza con facilidad.

Coral es el ente actancial pasivo colocado por Satanás. Este último es la expresión de un Destino a medio desvelar, es el personaje que dinamiza la evolución moral de los personajes masculinos: en lugar de su tradicional papel de agente del mal y del vicio se convierte en incitador del bien y de la virtud.

\section{Notas}

1. Jardiel Poncela, Enrique. 1990. Eloísa está debajo de un almendro. Las cinco advertencias de Satanás. Madrid: Espasa-Calpe, 238. En adelante se indicará el número de la página cada vez que se cite la obra teatral.

\section{Bibliografía}

Alvar, Manuel et al. 1975. El teatro y su crítica (reunión de Málaga de 1973). Málaga: Instituto de la Cultura de la Diputación Provincial de Málaga. 
Allemann, Beda. 1971. "La ironía como principio literario". Humboldt (Revista para el mundo hispanoamericano). (46): 32-8.

Aragonés, Juan Emilio. 1971. Teatro español de posguerra. Madrid: Publicaciones Españolas.

Bajtin, Mijail. 1989. La cultura popular en la Edad Media y en el Renacimiento: El contexto de François Rabelais. Madrid: Alianza Editorial.

Bousoño, Carlos. 1985. Teoría de la expresión literaria. Madrid: Editorial Gredos.

Garrido, Lenin. 1972. La imagen teatral. San José: Editorial Costa Rica.

Jardiel. Poncela, Enrique. 1994. Eloísa está debajo de un almendro. Las cinco tentaciones de Satanás. Madrid: Editorial Espasa Calpe.

Marquerie, Alfredo. 1959. Veinte años de teatro en España. Madrid: Editora Nacional.

Muñoz Molina, Antonio. 1993. El Robinson urbano. Barcelona: Seix Barral.

Pérez Coterillo, Moisés. 1995. "La escritura teatral pasa por taquilla". Abc Cultural (Suplemento del Abc). 190: 18.

Pérez Yglesias, María de los Angeles. 1983. "Ironía, dependencia y humor en la producción significante latinoamericana". Revista de Filología y Lingüística. 9 (1): 155-66.

Porras León, Rita María. 1995. El sentido del humor en La vida exagerada de Martín Romaña, del escritor peruano Alfredo Bryce Echenique. Tesis de maestría: Universidad de Costa Rica.

Rodríguez Alcalde, Leopoldo. 1973. Teatro español contemporáneo. Madrid: E.P.E.S.A.

Ruiz Ramón, Francisco. 1975. Historia del teatro español. Siglo XX. Madrid: Ediciones Cátedra.

Sánchez Vidal, Agustín. 1990. Sol y sombra (De cómo los españoles se apearon de las mayúsculas de la Historia, dotándose de vida cotidiana). Barcelona: Editorial Planeta.

Sastre, Alfonso. 1956. Drama y sociedad. Madrid: Editorial Taurus.

Urbano, Victoria. 1972. El teatro español y sus directrices contemporáneas. Madrid: Editora Nacional. 
